American Journal of Infectious Diseases 5 (2): 154-162, 2009

ISSN 1553-6203

(C) 2009 Science Publications

\title{
Effect of Aqueous Extract of Aegle marmelos Fruit on Adherence and $\beta$-Lactam Resistance of Enteropathogenic Escherichia coli by Down Regulating Outer Membrane Protein C
}

\author{
Subramaniya Bharathi Raja, Malliga Raman Murali, G.K. Malathi, \\ K. Anbarasu and S. Niranjali Devaraj \\ Department of Biochemistry, University of Madras, Guindy campus, Chennai-600025, India
}

\begin{abstract}
Problem statement: Enteropathogenic Escherichia Coli (EPEC) continue to be a major health problem, leading to death due to diarrhea, predominantly in children below the age of five. Due to evolution of multi drug resistance in EPEC and side effects caused to host by antibiotics necessitated a search for alternative medicines from medicinal plants. One such medicinal plant used since ancient times to cure diarrhea is Aegle marmelos. This study was done to investigate the effect of aqueous extract of Aegle marmelos fruit (AEAM) on outer membrane protein $\mathrm{C}$ (OmpC) of EPEC, which plays a key role in adherence and antibiotic resistance. Approach: Fixation of minimum inhibitory concentration. In presence and absence of AEAM antibiotic susceptibility test was performed. Expression analysis of $O m p C$ and $O m p F$ was carried out by RT-PCR of $E P E C$ in presence and absence of AEAM. Morphological changes of EPEC in presence and absence of AEAM were analyzed by TEM. In infant mouse ileal loop model, histological analysis, adherence of bacteria to ileal loops and Western blotting for caspase-3 and Hsp70 were done. Results: OmpC ( 42 kDa) a porin, played an important role in selective transport of nutrients and also acted as an adhesin, whereas $O m p F$ $(\sim 38 \mathrm{kDa})$ is also a porin which is non selective. Susceptibility of EPEC to $\beta$-lactam antibiotics in presence of AEAM can be attributed to down regulation of $O m p C$ and upregulation of $O m p F$. The changes in Omp expression also triggered morphological changes in EPEC. Histology and western blot of Hsp70 and Caspase-3 in rat ileal loop confirmed the effect of AEAM on attenuating the virulence of EPEC by preventing its infection due to loss of adherence. Loss of adherence was due to morphological changes and down regulation of $O m p C$ in $E P E C$. Conclusion: From this study, we concluded that the protection offered by AEAM against EPEC was due to down regulation of $O m p C$, leading to loss of adherence and up regulation of $O m p F$, which allowed the entry of $\beta$-lactam antibiotics into bacteria. Hence, AEAM, along with $\beta$-lactam antibiotics can be used in treatment of EPEC infections.
\end{abstract}

Key words: Porins, RT-PCR, $O m p F$

\section{INTRODUCTION}

Acute diarrhea is a common cause of death in developing countries and the second most common cause of infant deaths worldwide. According to a report in 2003, diarrhea accounts for $21 \%$ of all deaths below five years of age and causes 2.5 million deaths per year Kosek et $a l .^{[1]}$. These numbers remain relatively unchanged when compared with previous reports by Bern et al for the period of 1980-1990 ${ }^{[2]}$.

Even though there are many factors responsible for causing diarrhea (including osmotic imbalance, indigestion of diary products) enteric infection is the leading cause of diarrhea in developing countries.
About 10-15\% of diarrhea is caused by Enteropathogenic Escherichia coli (EPEC), which stands next to Enterotoxigenic Escherichia coli (ETEC), which cause about $20 \%$ of diarrhea.

Enteropathogenic Escherichia coli is a gram negative bacterium that is commonly found in the lower intestine of warm-blooded animals. EPEC lack fimbriae, ST and LT toxins, but they utilize an adhesin known as intimin to bind to host intestinal cells ${ }^{[3-5]}$. This virotype has an array of virulence factors that are similar to those found in Shigella. Adherence to the intestinal mucosa causes a rearrangement of actin in the host cell, leading to significant deformation ${ }^{[6]}$. EPEC cells are moderately-invasive and elicit an

Corresponding Author: S. Niranjali Devaraj, Department of Biochemistry, University of Madras, Guindy Campus Chennai-600025, Tamilnadu, India Tel: 91-44-22202730 Fax: 91-44-22352494 
inflammatory response. Changes in intestinal cell ultrastructure due to "attachment and effacement" are likely to be the prime cause of diarrhea in those afflicted with EPEC ${ }^{[7]}$.

Many factors such as the plasmid antigens, antioxidant enzymes, lipopolysaccharides, intimin (an outer membrane protein) contribute to its virulence. Frequency of strains resistant to ampicillin, trimethoprim-sulfamethoxazole, streptomycin, Ciproflaxin, chloramphenicol, tetracycline and cephalosporins (ceftriaxone or ceftazidime) is a cause of growing concern. A situation such as this overpowering mankind, poses another facet to be explored: turn back to nature. There is a growing interest in traditionally used medicinal plants which produce a variety of compounds having therapeutic properties $^{[8-10]}$. One such medicinal plant used since ancient time to cure diarrhea is Aegle marmelos Correa, commonly known as Bael and belongs to the family Rutaceae. Its stem, bark, root, leaves and fruits have medicinal value and it has a long tradition as a herbal medicine. Bael fruit is rich in 2 furocoumarins; psoralen and marmelosin ${ }^{[11]}$.

In the present study, we have shown the effectiveness of the aqueous extract of Aegle marmelos (AEAM) fruit on inhibition of adhesion of Enteropathogenic Escherichia coli to intestine, vulnerability of $\beta$-lactam resistant clinical isolates of EPEC towards $\beta$-lactam antibiotics. Both, inhibition of binding to intestine and vulnerability to $\beta$-lactam by AEAM are due to the down regulation of $O m p C$.

\section{MATERIALS AND METHODS}

Bacterial strains and growth conditions: Clinical isolates of Enteropathogenic Escherichia coli were obtained from, the Head, Department of Microbiology, Sri Ramachandara Medical College and Research Institute, Chennai, India. A single colony from LuriaBertani agar plate was inoculated in Luria-Bertani broth and incubated for $18 \mathrm{~h}$ at $37^{\circ} \mathrm{C}$, with constant shaking at $200 \mathrm{rev} \mathrm{min}^{-1}$.

Preparation of Aqueous Extract of Aegle marmelos (AEAM): Fruits of Aegle marmelos were collected from Vaniyambadi, Tamil Nadu, India. The fruits were shade dried, seeds were removed and fruits were ground mechanically. $500 \mathrm{~g}$ of powdered fruit were extracted with 1 liter of water for $12 \mathrm{~h}$. The resulting extract was filtered using Whatman No. 1 filter paper. The filtrate was evaporated in vacuum to give a residue, (yield 2.98\%).
Determination of Minimum Inhibitory Concentration (MIC): The antimicrobial susceptibility test was done by the 2-fold broth macrodilution method according to the National Committee for Clinical Laboratory Standards ${ }^{[12]}$. The wild bacteria and bacteria treated with AEAM at final concentrations of about $7 \mathrm{X}$ $10^{5} \mathrm{cfu} \mathrm{mL}^{-1}$ were separately inoculated into LB broth with various concentrations of Ampicillin, Penicillin and Vancomycin. The MIC of each antibiotic was determined by enumerating colonies on the agar plates after incubation for $18 \mathrm{~h}$ at $37^{\circ} \mathrm{C}$. The percentage of growth inhibition was calculated by comparing the growth of wild bacteria.

Animals: Male $B A L B / c$ mice weighing 120-150 g were obtained from TANUVAS-LAMU, Madhavaram, Chennai. Animals were fed normal pelleted diet and water, ad libitum. All the experiments were carried out according to guidelines provided by the Institutional Animals Ethics Committee (IAEC) (IAEC No.01/015/06), CPCSEA No. 360/01/a CPCSEA.

Rat ileal loop ligation assay: Experimental diarrhea was induced by EPEC according to Arm et al. ${ }^{[13]}$. To assess the fluid accumulation and dilation of intestinal loops, male $B A L B / c$ mice (4-5 weeks old) were fasted for $24 \mathrm{~h}$ before being anaesthetized with sodium pentothal (40 mg kg-1 body weight). After making a small incision in the abdominal region, inocula of $10^{9}$ CFU in $0.5 \mathrm{~mL}$ of $\mathrm{PBS}, \mathrm{pH} \mathrm{7.4,} \mathrm{were} \mathrm{injected} \mathrm{into}$ ligated ileal loops in ileo caecal junction and the mice were allowed to live for $6 \mathrm{~h}$. Histological analysis and analysis of adherence of bacteria to intestinal loop were performed according to Zychlinsky et al. ${ }^{[14]}$.

Plasmid isolation: Isolation of plasmid DNA was done using plasmid mini preparation kit obtained from GeNei $^{\text {TM }}$, Bangalore, according to manufacturer's instruction. Plasmids were detected by electrophoresis in $0.8 \%$ agarose gel containing $0.5 \mu \mathrm{g} \mathrm{mL}^{-1}$ of ethidium bromide and photographed with UV-light illumination $^{[15]}$.

Preparation of membrane and cytosol fractions: Outer membrane proteins were isolated as described previously ${ }^{[16]}$. Overnight cultures were centrifuged for $5 \mathrm{~min}$ at $7000 \mathrm{~g}$. Pellets were washed once with $20 \mathrm{mM}$ Tris, $10 \mathrm{mM}$ EDTA, $\mathrm{pH} 8$ (TE), then resuspended in the same buffer. Bacteria were disrupted by sonication for 1 min, followed by a $2 \mathrm{~min}$ rest, then an additional $1 \mathrm{~min}$ sonication. Samples were centrifuged for $5 \mathrm{~min}$ at $7000 \mathrm{~g}$ to remove debris and the resulting supernatant was 
centrifuged for $1 \mathrm{~h}$ at $60,000 \mathrm{~g}$ at $4^{\circ} \mathrm{C}$ The clear supernatant was retained as cytosolic fraction. The pellet was resuspended in TE and the protein concentration was estimated ${ }^{[17]}$. Protein concentration was adjusted to $5 \mathrm{mg} \mathrm{mL}^{-1}$ and solubilised with sodium lauryl sarcosinate $1 \% \mathrm{w} / \mathrm{v}$ (final concentration) at $4^{\circ} \mathrm{C}$ for $1 \mathrm{~h}$. Samples were centrifuged again for $1 \mathrm{~h}$ at $60,000 \mathrm{~g}$ at $4^{\circ} \mathrm{C}$ and the supernatant was taken for analysis of inner membrane fraction and the pellet was resuspended in 1\% SDS and boiled for $10 \mathrm{~min}$. Protein concentrations of cytosol and membrane fractions were estimated and equal concentration of protein fraction were run on Sodium Dodecyl Sulfate-Polyacrylamide Gel Electrophoresis (SDS-PAGE). The gels were stained with Coomassie brilliant blue R-250.

Isolation of RNA: Exponentially growing bacterial cells reaching the OD of 1.0 at $540 \mathrm{~nm}$ were harvested by centrifugation $\left(5 \mathrm{~min}, 3800 \mathrm{~g}, 4^{\circ} \mathrm{C}\right)$. For preparation of total RNA, the phenol -guanidinium thiocyanate based Tri Reagent ( $\mathrm{GeNei}^{\mathrm{TM}}$, Bangalore) was used. To $10^{8}$ bacterial cells, $1 \mathrm{~mL}$ of Tri reagent was added and lysed by repetitive pipetting and allowed to stand for 5 min followed by addition of $200 \mu \mathrm{L}$ of chloroform for phase separation. Vigorously vortexed for $15 \mathrm{sec}$ and allowed to stand for $15 \mathrm{~min}$ followed by centrifugation at $12000 \mathrm{~g}$ for $15 \mathrm{~min}$ at $4^{\circ} \mathrm{C}$. The upper aqueous layer containing RNA was transferred to a fresh sterile DEPC treated microfuge tube. To this, $250 \mu \mathrm{L}$ of ice cold isopropanol was added, gently mixed and allowed to stand for $10 \mathrm{~min}$ and centrifuged at $12000 \mathrm{~g}$ for $15 \mathrm{~min}$ at $4^{\circ} \mathrm{C}$. The supernatant was discarded and the RNA pellet was washed with $1 \mathrm{~mL}$ of $75 \%$ ethanol in DEPC treated water and again centrifuged at $14000 \mathrm{~g}$ for $10 \mathrm{~min}$ at $4^{\circ} \mathrm{C}$ to get total RNA. This pellet was dissolved in $25 \mu \mathrm{L}$ of sterile RNase free water by heating at $55^{\circ} \mathrm{C}$ for $20 \mathrm{~min}$ and stored at $-20^{\circ} \mathrm{C}$ until use.

RT-PCR: To synthesize cDNA, a reverse transcription reaction solution containing the following reagents: $1.0 \mu \mathrm{g}$ total RNA in RNase/DNase-free water and $1.5 \mu \mathrm{L}$ random hexamer primer $\left(\mathrm{GeNei}^{\mathrm{TM}}\right.$, Bangalore) were incubated for $10 \mathrm{~min}$ at $72^{\circ} \mathrm{C}$ and chilled immediately. To this, $5.0 \mu \mathrm{L}$ premixed $10 \mathrm{mM}$ dNTP solution (GeNei ${ }^{\mathrm{TM}}$, Bangalore), $3.0 \mu \mathrm{L} 10 \mathrm{X} \mathrm{M}-\mathrm{MLV}$ reverse transcriptase buffer $\left(\mathrm{GeNei}^{\mathrm{TM}}\right.$, Bangalore), $1.0 \mu \mathrm{L}$ (200 units $\mu \mathrm{L}^{-1}$ ) M-MLV reverse transcriptase $\left(\mathrm{GeNei}^{\mathrm{TM}}\right.$, Bangalore), were added and made up to $50 \mu \mathrm{L}^{-1}$ using sterile RNase/DNase-free water.

To amplify the cDNA, Polymerase Chain Reaction (PCR) ready mix $\left(\mathrm{GeNei}^{\mathrm{TM}}\right.$, Bangalore) was used according to manufacturer's instruction. All PCR samples were denatured at $94^{\circ} \mathrm{C}$ for 5 min prior to cycling and were extended for $10 \mathrm{~min}$ at $72^{\circ} \mathrm{C}$ following cycling. The PCR assay using primers was performed for 39 cycles at $94^{\circ} \mathrm{C}$ for $60 \mathrm{~s}, 60^{\circ} \mathrm{C}$ for $60 \mathrm{~s}$ and $72^{\circ} \mathrm{C}$ for $60 \mathrm{~s}$. Primers for ompF, отрC, отрA, ompR, envZ and 16s rRNA are shown in Table 1. Primers were designed using primer 3 software available free on http://fokker.wi.mit.edu/primer3/input.htm and nucleic acid sequence was accessed from http://www.ncbi.nlm.nih.gov/entrez/viewer.fcgi?val=ID (Table 1). The primers were purchased from Integrated DNA technologies, USA.

TEM studies: Bacterial strains were grown overnight, with and without the extract, in LB broth and washed thrice with PBS. The cells were fixed in 3\% glutraldehyde, post fixed with $1 \%$ osmium tetra oxide and subjected to transmission electron microscopy to look for changes in morphology of the bacteria.

Antibiotic sensitivity test by disc diffusion method: Antibiotic sensitivity of test strains was determined by the standard Disc diffusion method against Ampicillin (A10) Penicillin (P 30) Norfloxin (N30) Vancomycin (Va30) Chloramphenicol (C30) Novobiocin (Nv 30) and Carbenicillin (Cb100) Antibiotic discs were purchased from Hi-Media Pvt. Ltd. (Mumbai, India).

$\boldsymbol{\beta}$-Lactamase assays: Crude $\beta$-lactamase extracts were prepared from $5 \mathrm{~mL}$ of overnight cultures. Bacterial cells containing $\beta$-lactamase were grown to mid-log phase (optical density at $540 \mathrm{~nm}$ : 0.5) in LB broth containing $100 \mathrm{mg}$ of ampicillin $\mathrm{mL}^{-1}$. The cells were pelleted, washed and resuspended in $500 \mathrm{~mL}$ of $50 \mathrm{mM}$ Tris- $\mathrm{HCl}$ buffer, $\mathrm{pH}$ 7.4. A $40 \mathrm{mg} \mathrm{mL}^{-1}$ stock solution of freshly prepared lysozyme in Tris- $\mathrm{HCl}$ buffer was added to a final concentration of $10 \mathrm{mg} \mathrm{mL}^{-1}$ and bacterial cells were incubated for $15 \mathrm{~min}$ at room temperature. EDTA was added to a final concentration of $1 \mathrm{mM}$ and the mixture was gently shaken for $10 \mathrm{~min}$. The cell suspension was clarified by centrifugation at $14,000 \mathrm{~g}$ for $15 \mathrm{~min}$ and the supernatant was collected.

Table 1: Primer sequence of $16 s$ rRNA, ompR, ompC, envZ, ompA and $o m p F$ and product size.

\begin{tabular}{|c|c|c|c|}
\hline S. No. & Gene & Primer pair & $\begin{array}{l}\text { Product } \\
\text { size (bp) }\end{array}$ \\
\hline 1. & $16 s r R N A$ & $\begin{array}{l}\text { Left 5'cagccacactggaactgaga 3' } \\
\text { Right 5'gttagccggtgcttcttctg 3' }\end{array}$ & 204 \\
\hline 2. & отрС & $\begin{array}{l}\text { Left 5'aattcggtggcgacacttac 3' } \\
\text { Right 5'acgcagagctttacgaccat 3', }\end{array}$ & 209 \\
\hline 3. & ompF & $\begin{array}{l}\text { Left } 5 \text { ' aggctttggtatcgttggtg } 3 \text {, } \\
\text { Right } 5 \text { 'tgcgcaactaacagaacgtc } 3 \text {, }\end{array}$ & 237 \\
\hline 4. & ompR & $\begin{array}{l}\text { Left 5' cgtcgctaatgcagaacaga 3' } \\
\text { Right 5'ggtccacttcttcccctttc 3' }\end{array}$ & 176 \\
\hline
\end{tabular}


$\beta$-Lactamase activity in the supernatant was measured with the chromogenic cephalosporin nitrocefin The amount of protein in each $\beta$-lactamase preparation was determined by Lowry et al. ${ }^{[17]}$. The specific activity present in each sample was estimated by measuring the hydrolysis of $100 \mathrm{mM}$ nitrocefin at $25^{\circ} \mathrm{C}$ in a spectrophotometer at $482 \mathrm{~nm}$. Specific activity was defined as $\mathrm{U} \mathrm{mg}^{-1}$ of protein. One unit was defined as the amount of nitrocefin hydrolyzed (micromolar) $\mathrm{min}^{-1}$.

\section{RESULTS}

Minimum inhibitory concentration of aqueous extract of Aegle marmelos: In the serial dilution experiment, the numbers of colonies $\left(\mathrm{CFU} \mathrm{mL} \mathrm{mL}^{-1}\right)$ were gradually decreased with increase in AEAM concentration and the optimal inhibitory concentration of the extract was found to be $500 \mu \mathrm{g} \mathrm{mL}^{-1}$. The concentration below this i.e., $250 \mu \mathrm{g} \mathrm{m} \mathrm{L}{ }^{-1}$, was used for further study.

Rat ileal loop assay: Infection with AEAM-treated Enteropathogenic Escherichia coli showed almost normal architecture of the small intestine (Fig. 1c) when compared with wild Enteropathogenic Escherichia coli which caused shortening and edema of villi, ulceration and inflammatory infiltration of hemorrhagic exudates in the luminal surface of the mucosa. (Fig. 1b) Uninfected loop and loop injected with AEAM alone showed normal architecture (Fig. 1a and d).

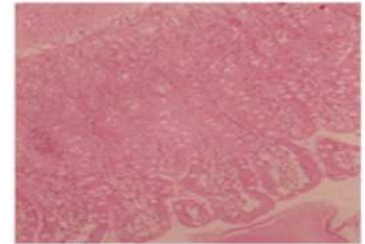

(a)

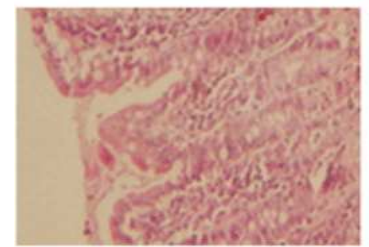

(c)

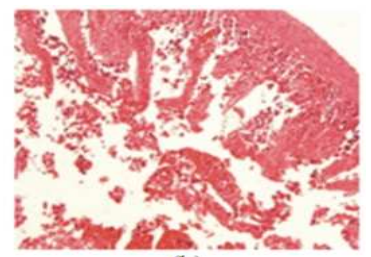

(b)

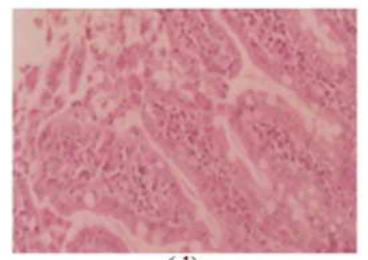

(d)
Fig. 1: Histology of wild and treated EPEC infected loops. (a): Control loop; (b): Wild EPEC infected loop; (c): loop injected with drug alone; (d): Treated EPEC infected loop
Western blot analysis of ileal loop: Figures $2 \mathrm{a}$ and $\mathrm{b}$ show the western blot analysis of wild and AEAMtreated EPEC infected loop for expression of Hsp70 and Caspase-3, respectively. This was done to assess the apoptosis caused due to infection of wild and AEAM treated EPEC in ileal loop. Increase in Hsp 70 levels and decrease in activated Caspase- 3 in AEAM treated EPEC-infected loop clearly shows loss of virulence

Plasmid profile: No significant difference in plasmid profile was seen in treated Enteropathogenic Escherichia coli when compared with the wild type (Fig. 3).
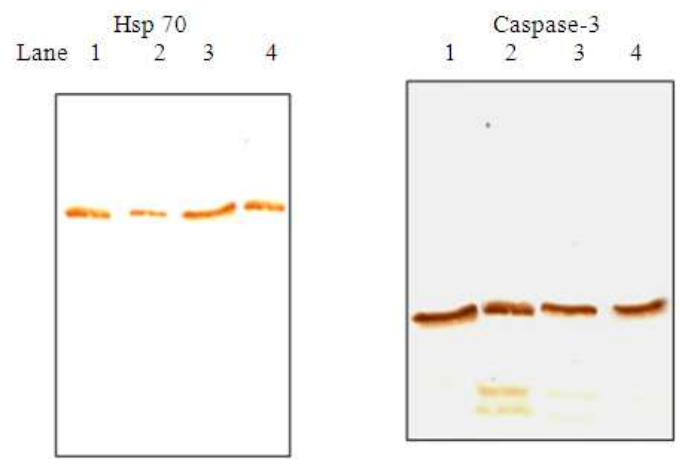

Fig. 2: Western blot analysis of wild and treated EPEC infected loops. (1): Control; (2): Wild EPEC infected loop; (3): AEAM Treated EPEC infected loop; (4): Drug control

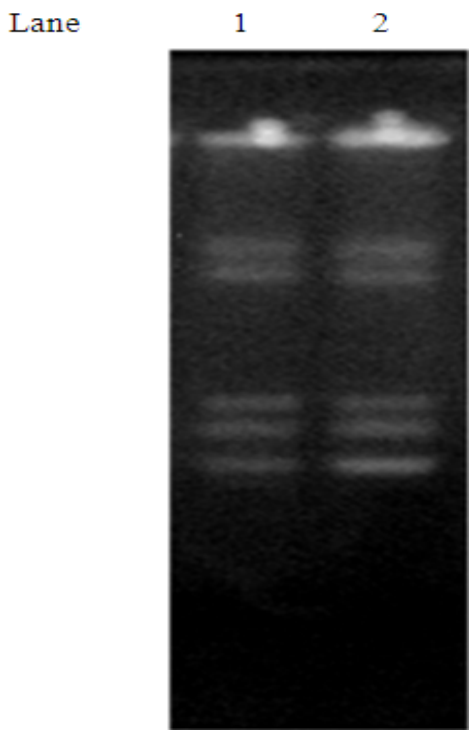

Fig. 3: Effect of AEAM on plasmid profile of EPEC. (1): Wild EPEC; (2): AEAM treated EPEC 
Am. J. Infect. Dis., 5 (2): 154-162, 2009

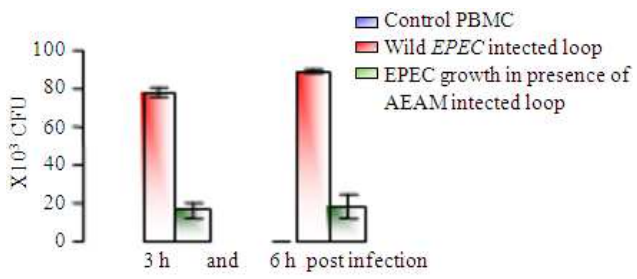

Fig. 4: Adherence of EPEC to intestinal mucosa

Adherence of Enteropathogenic Escherichia coli to ileal loop: Adherence of bacteria to ileal loop was analyzed by plating serially diluted loop tissue extract on selective medium MacConkey agar. A $62 \%$ decrease in adherence of AEAM treated Enteropathogenic Escherichia coli to ileal loop was observed when compared to adherence of wild Enteropathogenic Escherichia coli (Fig. 4).

Analysis of cytosolic and outer membrane proteins: Enteropathogenic Escherichia coli was grown overnight at $37^{\circ} \mathrm{C}$ in medium without and with AEAM $\left(250 \mu \mathrm{g} \mathrm{mL}^{-1}\right)$. The proteins were fractionated and subjected to SDS-PAGE. The protein profile of the cytosolic and outer membrane are shown in Fig. 5 respectively. Cytosolic fraction of Enteropathogenic Escherichia coli grown in the presence of AEAM showed significant difference with decreased levels of $\sim 26 \mathrm{kDa}$ protein (Fig. 2a, lane 1 versus lane 2).

In the presence of AEAM, the outer membrane fraction of Enteropathogenic Escherichia coli showed significantly higher levels of $\sim 38 \mathrm{kDa}$ protein and significantly lower levels of $\sim 42 \mathrm{kDa}$ protein when compared with their levels in Enteropathogenic Escherichia coli grown in the absence of AEAM (lane 4 versus lane 5). In addition, there were other minor differences between protein profiles of the bacteria grown in the presence and in the absence of AEAM.

Analysis of expression of $\mathrm{OmpF}, \mathrm{OmpC}, \mathrm{ompA}$, $o m p R, e n v Z$ and 16s rRNA: In our study, we used RTPCR to determine the expression levels of the porin transcripts. This method potentially eliminates some of the difficulties associated with subjective interpretation of outer membrane protein profiles. Enteropathogenic Escherichia coli grown in presence of AEAM showed decreased amounts of RNA transcripts of the $O m p C$ and $o m p R$ genes compared to the Enteropathogenic Escherichia coli grown in absence of AEAM (Fig. 3a), whereas level of RNA transcript of $O m p F$ was increased in Enteropathogenic Escherichia coli grown in presence of AEAM when compared to Enteropathogenic Escherichia coli grown in absence of AEAM (Fig. 6). 16s rRNA was used as internal control.

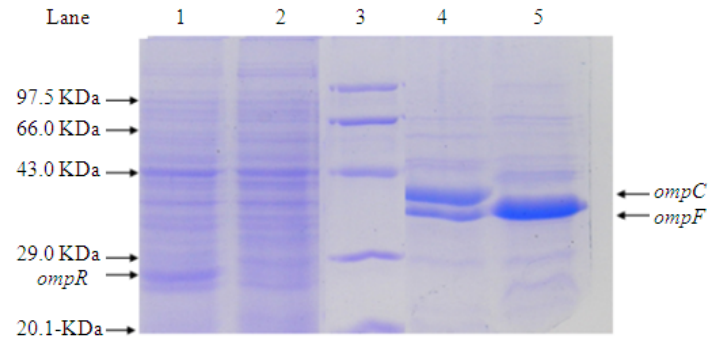

Fig. 5: Analysis of cytosolic and outer membrane protein. (1): Cytosolic protein profile of EPEC grown in absence of AEAM; (2): Cytosolic protein profile of EPEC grown in presence of AEAM; (3): Marker; (4): Outer membrane protein profile of EPEC grown in absence of AEAM; (5): Outer membrane protein profile of EPEC grown in absence of AEAM

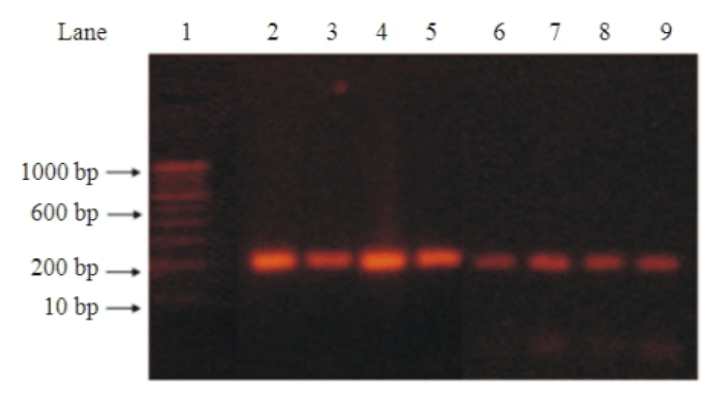

Fig. 6: Expression analysis of ompF, ompC, ompR and 16s rRNA. 2\% Agarose gel showing expression pattern of ompF, ompC, ompR and 16s rRNA of $E P E C$ grown in absence and presence of AEAM. (Lane 8 and 9): EPEC grown in absence and presence of AEAM respectively, representing amplified product of $16 \mathrm{~s} r R N A$, showing almost equal expression; (Lane 2 and 3): EPEC grown in absence and presence of AEAM respectively, representing amplified product of $о т p C$; (Lane 4 and 5): EPEC grown in absence and presence of AEAM respectively, representing amplified product of ompR; (Lane 6 and 7): EPEC grown in absence and presence of AEAM respectively, representing amplified product of ompF; (Lane 1): Molecular weight markers

TEM analysis: Figure 7 shows the morphological analysis of wild and AEAM treated EPEC. In EPEC grown with AEAM, cells were shrunken in size. Cytoplasmic materials were condensed along with irregularities in outer membrane. The distinction between outer membrane and the plasma membrane was not clearly seen. 
Table 2: Antibiotic sensitivity test for in absence and presence of AEAM (inhibition zone in $\mathrm{Cm}$ )

\begin{tabular}{lllll}
\hline & & & \multicolumn{2}{c}{$\begin{array}{l}\text { Grown in presence } \\
\text { of AEAM }\end{array}$} \\
\hline Antibiotics & & & 3.8 & $\mathrm{~S}$ \\
Ampicillin (A10) & 0.0 & $\mathrm{R}$ & 2.8 & $\mathrm{~S}$ \\
Penicillin (P 30) & 0.0 & $\mathrm{R}$ & 4.9 & $\mathrm{~S}$ \\
Norfloxin (N30) & 4.8 & $\mathrm{~S}$ & 2.1 & $\mathrm{~S}$ \\
Vancomycin (Va30) & 0.0 & $\mathrm{R}$ & 0.0 & $\mathrm{R}$ \\
Chloramphenicol (C30) & 0.0 & $\mathrm{R}$ & 2.4 & $\mathrm{~S}$ \\
Novobiocin (Nv 30) & 1.0 & $\mathrm{R}$ & $\mathrm{R}$ \\
Carbenicillin (Cb100) & 1.2 & $\mathrm{R}$ & 1.2 & $\mathrm{R}$ \\
\hline
\end{tabular}

The above table represents inhibitory zones of Shigella dysenteriae and Shigella flexneri in absence and presence of AEAM. R: Resistance; $\mathrm{S}$ : Sensitive (Values in above table represent average of three experiments)
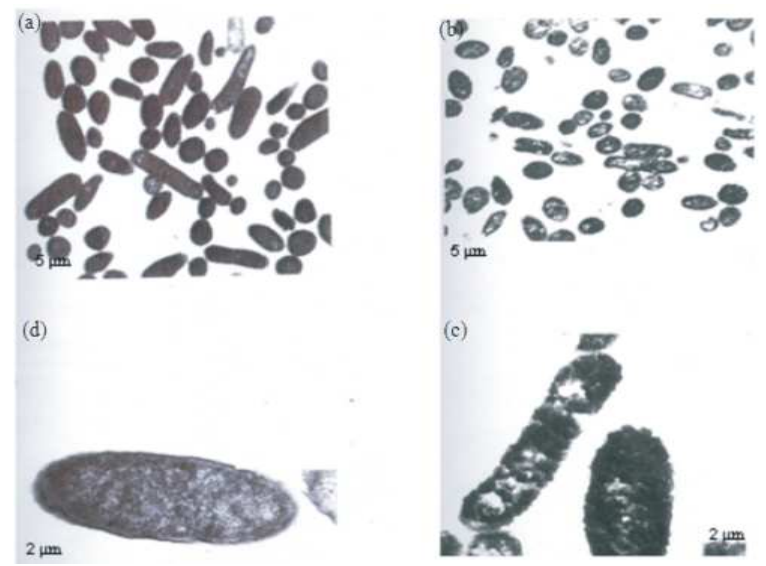

Fig. 7: TEM analysis of wild and AEAM treated EPEC. (a): EPEC grown in absence of AEAM at $1000 \mathrm{x} ;(\mathrm{b})$ : EPEC grown in presence of AEAM at $1000 \mathrm{x}$; (c): EPEC grown in absence of AEAM at $65000 \mathrm{x}$; (d): EPEC grown in presence of AEAM at $65000 \mathrm{x}$

Antibiotic sensitivity test by disc diffusion method: Antibiotic sensitivity of both wild and AEAM treated Enteropathogenic Escherichia coli was qualitatively assessed by the presence or absence of inhibition zone and zone diameter, respectively, as given in Table 2 and Fig. 8. Inhibition zones of Enteropathogenic Escherichia coli grown in the presence of AEAM were $3.8,2.8$ and 2.1 for penicillin, ampicillin and vancomycin, respectively. The susceptibility tests were repeated for each antibiotic at least three times.

Assay of $\beta$-lactamase activity: As shown in the Fig. 9, difference in $\beta$-lactamase activity was not observed in overnight grown cultures of Enteropathogenic Escherichia coli in LB medium without and with $\operatorname{AEAM}\left(250 \mu \mathrm{g} \mathrm{mL}^{-1}\right)$.
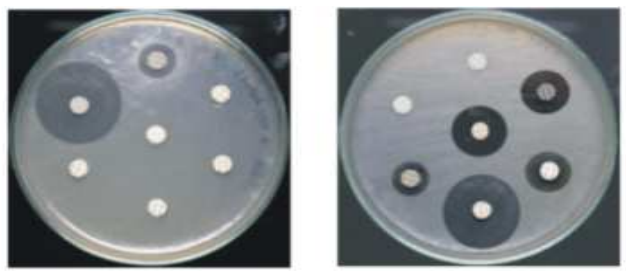

Fig. 8: Antibiotic sensitivity of Shigella dysenteriae and Shigella flexneri grown in absence and presence of AEAM. (a): Grown in absence of AEAM; (b): Grown in presence of AEAM

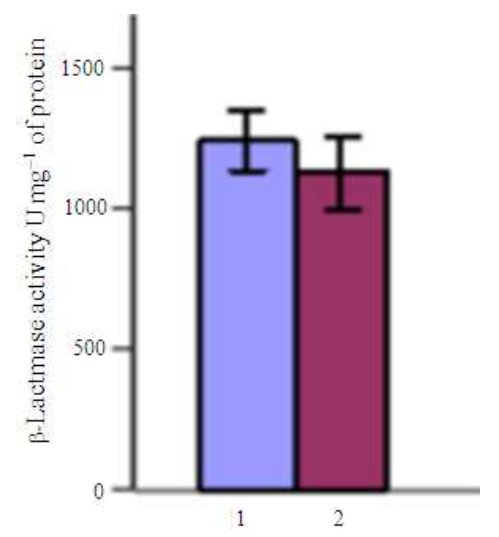

Fig. 9: $\beta$-Lactmase activity of wild and AEAM treated EPEC. (1): Wild EPEC; (2): AEAM Treated EPEC

\section{DISCUSSION}

Evolution of multi-drug resistance in Enteropathogenic Escherichia coli as well as adverse side effects of certain antibiotics have stimulated immense interest in the search for alternative antimicrobial strategies to combat these organisms. In the present study, we showed the inhibition of binding of EPEC to intestine and also the vulnerability to $\beta$ lactam antibiotics when Enteropathogenic Escherichia coli are grown in presence of AEAM.

Infection of mouse ileal loop with AEAM $\left(250 \mu \mathrm{g} \mathrm{mL}^{-1}\right)$ treated Enteropathogenic Escherichia coli showed almost normal architecture and apoptotic analysis showed low levels of activated form of Caspase 3, ensuring the loss of pathogenesis. This may be due to the effect of AEAM on the $69 \mathrm{~kb}$ plasmid which plays a vital role in pathogenesis and virulence of EPEC $^{[18]}$. However, loss of plasmid was not observed in AEAM treated Enteropathogenic Escherichia coli.

The pathogenesis of EPEC primarily involves the adherence of the pathogen to intestinal mucosa. 
Adherence of Enteropathogenic Escherichia coli grown in presence and absence of AEAM were analyzed, which reveled almost $60 \%$ decrease in bacterial adherence in loop infected with Enteropathogenic Escherichia coli grown in presence of AEAM when compared with loop infected with Enteropathogenic Escherichia coli grown in absence of AEAM.

The adherence of EPEC principally involves binding of the pathogen to intestinal mucosa with the help of the $\sim 90 \mathrm{kDa}$ outer membrane protein, intimin. Intimin, an adhesin of Enteropathogenic Escherichia coli, binds to host intestinal cells and causes a rearrangement of actin in the host cell, leading to significant deformation and elicits an inflammatory response $^{[19]}$. Hence, outer membrane protein profiles were analyzed. But there were no significant changes in the levels of $\sim 90 \mathrm{kDa}$ outer membrane protein in both EPEC grown in presence and absence of AEAM. However, in the presence of AEAM, the outer membrane fraction of Enteropathogenic Escherichia coli showed significantly higher levels of $\sim 38 \mathrm{kDa}$ protein and significantly lower levels of $\sim 42 \mathrm{kDa}$ protein when compared with EPEC grown in the absence of AEAM.

Further, these outer membrane proteins of $\sim 42$ and $\sim 38 \mathrm{kDa}$ were identified as $O m p C$ and $O m p F$, respectively, by correlating the decrease in levels of RNA transcript of $O m p C$ and increase in levels of RNA transcript of $O m p F$ in EPEC grown in the presence of AEAM. In another enteric pathogen Shigella, $\sim 42 \mathrm{kDa}$ protein $O m p C$ is involved in adherence and invasion of epithelial cells ${ }^{[20]}$. Hence, decreased levels of $O m p C$ in Enteropathogenic Escherichia coli grown in the presence of AEAM can be associated with observed loss of adherence.

$O m p C$ and $O m p F$ play an important role in osmoregulation. The effect of alteration of outer membrane protein on morphology of Enteropathogenic Escherichia coli grown in the presence and absence of AEAM was studied by TEM. Enteropathogenic Escherichia coli grown in the presence AEAM, showed shrinkage of size and condensation of cytoplasmic materials with irregularities of outer membrane proteins when compared to Enteropathogenic Escherichia coli grown in the absence AEAM. Morphological changes and irregularities in outer membrane proteins of Enteropathogenic Escherichia coli grown in the presence AEAM also contribute to inhibition of adherence and loss of virulence.

$O m p C$ and $O m p F$ not only play vital role in osmoregulation and adherence, they play a crucial role in antibiotic sensitivity of bacteria by acting as permeability factor. Hence, antibiotic susceptibility of Enteropathogenic Escherichia coli grown in the absence and in the presence of AEAM $\left(250 \mu \mathrm{g} \mathrm{mL} \mathrm{m}^{-1}\right)$ was compared. Zone of inhibition for ampicillin (A10), penicillin (P30), vancomycin (Va30) were observed in Enteropathogenic Escherichia coli grown in the presence of AEAM, which were not found in Enteropathogenic Escherichia coli grown in the absence of AEAM.

The large plasmids of Enteropathogenic Escherichia coli are necessary for their pathogenesis and antibiotic resistance ${ }^{[21,22]}$. However, loss of plasmid was not observed in both Enteropathogenic Escherichia coli grown in presence and absence of AEAM. Also, $\beta$-lactamase activity of the Enteropathogenic Escherichia coli grown in the presence and in the absence of AEAM was unchanged. The observed antibiotic resistance of Enteropathogenic Escherichia coli grown in presence of AEAM is correlated to increased levels of $O m p F$, which allows the permeability of these antibiotics. In Shigella also, AEAM affected the $\beta$-lactam resistance by up regulation of $O m p F^{[23]}$.

The reciprocal transcription of $O m p F$ and $O m p C$ is regulated by the active form of $\mathrm{OmpR}^{[24]}$ and env $\mathrm{Z}$ which phosphorylates OmpR by its histidine kinase and dephosphorylates by its phosphatase activity ${ }^{[25]}$. Differential expression of $O m p F$ and $O m p C$ is a direct consequence of the intracellular concentrations of the active form of $\mathrm{OmpR}^{[26]}$. Over expression of $O m p F$ is due to decreased expression of $\sim 26 \mathrm{kDa}$ protein (as seen in SDS PAGE) and lower levels of RNA transcript of ompR (by RT-PCR) in Enteropathogenic Escherichia coli grown in presence of AEAM.

\section{CONCLUSION}

From this study, we conclude that the protection offered by AEAM against EPEC is due to down regulation of $O m p C$, leading to loss of adherence and up regulation of $O m p F$, which allowed the entry of $\beta$ lactam antibiotics into bacteria. Hence, AEAM, along with $\beta$-lactam antibiotics, can be used in treatment of EPEC infections.

\section{REFERENCE}

1. Kosek, M., C. Bern and R.L. Guerrant, 2003. The magnitude of the global burden of diarrhoeal disease from studies published 1992-2000. Bull. World Health Org., 81: 197-204. DOI 10.1590/S0042-96862003000400003

2. Bern, C., J. Martines, I. De Zoysa and R.I. Glass, 1992. The magnitude of the global problem of diarrhoeal disease: A ten-year update. Bull. World Health Org., 70: 705-714. http://www.ncbi.nlm.nih.gov/pubmed/1486666 
3. Adu-Bobie J., G. Frankel, C. Bain, A.G. Goncalves, L.R. Trabulsi, G. Douce, S. Knutton, G. Dougan, 1998. Detection of intimins alpha, beta, gamma and delta, four intimin derivatives expressed by attaching and effacing microbial pathogens. J. Clin. Microbiol., 36: 662-668.

http://www.ncbi.nlm.nih.gov/pubmed/9508292

4. Malish, H.R., N.L. Freeman, D.V. Zurawski and P. Chowrashi et al., 2003. Potential role of the EPEC Translocated intimin receptor (Tir) in host apoptotic events. Apoptosis, 8: 179-190. http://www.ncbi.nlm.nih.gov/pubmed/12766478

5. Gansheroff, L.J., M.R. Wachtel, A.D. O'Brien, 1999. Decreased adherence of enterohemorrhagic Escherichia coli to HEp-2 cells in the presence of antibodies that recognize the C-terminal region of intimin. Infect Immunol., 67: 6409-6417. http://www.ncbi.nlm.nih.gov/pubmed/10569757

6. Gouin, E., M.D. Welch and P. Cossart, 2005. Actin-based motility of intracellular pathogens. Curr. Opin. Microbiol., 8: 35-45. http://www.ncbi.nlm.nih.gov/pubmed/15694855

7. Arbeloa, A., R.R. Bulgin, G. MacKenzie, R.K. Shaw and M.J Pallen et al., 2008. Subversion of actin dynamics by EspM effectors of attaching and effacing bacterial pathogens. Cell Microbiol., 10: 1429-1441.

http://www.ncbi.nlm.nih.gov/pubmed/18331467

8. Iyengar, M.A., 1985. Study of Crude Drugs. 2nd Edn., College of Pharmaceutical Sciences. Manipal, pp: 13-78.

9. Chopra, R.N., S.L. Nayer and I.C. Chopra, 1992. Glossary of Indian Medicinal Plants. 3rd Edn., Council of Scientific and Industrial Research, New Delhi, pp: 7-246.

10. Harborne, S.B. and H. Baxter, 1995. Phytochemical Dictionary. A Handbook of Bioactive Compounds from Plants. Taylor and Francis, London, ISBN: 0850667364.

11. Dikshit, B.B.L. and S.L. Dutt, 1932. The constitution of marmelosin Part I. J. Ind. Chem. Soc., 9: 271-279.

12. National Committee for Clinical Laboratory Standards (NCCLS), 1997. Methods for Dilution Antimicrobial Susceptibility Tests for Bacteria that Grow Aerobically. Approved Standard M7-A4, 4th Edn., Wayne, PA., USA. ISBN: 1-56238-309-4.

13. Arm, H.G., T.M. Floyd and J.E. Faber, 1965. Use of ligated segments of rabbit small intestine in experimental shigellosis. J. Bacteriol., 89: 803-809. http://www.pubmedcentral.nih.gov/articlerender.fc gi ?artid $=277540$
14. Zychlinsky, A., K. Thirumalai, J. Arondel, J.R. Cantey, A.O. Aliprantis and P.J. Sansonetti, 1996. In vivo apoptosis in Shigella flexneri infections. Infect. Immunol.,64:5357-5365. http://www.ncbi.nlm.nih.gov/pubmed/8945588

15. Sambrook, E.F. and T. Fritsch, 1989. Maniatis Molecular cloning: A Laboratory Manual. Cold Spring Harbor Laboratory, Cold Spring Harbor, New York, ISBN: 10: 0879693096, pp: 1659.

16. Kumar, S.S., K. Sankaran, R. Haigh, P.H Williams and A. Balakrishnan, 2001 Cytopathic effects of outer-membrane preparations of enteropathogenic Escherichia coli and co-expression of maltoporin with secretory virulence factor, EspB. J. Med. Microbiol., 50: 602-612.

http://jmm.sgmjournals.org/cgi/content/short/50/7/ 602

17. Lowry, O.H., N.J. Rosebrough, A.L. Farr and R.J. Randall, 1951. Protein measurement with the Folin phenol reagent. J. Biol. Chem., 193: 265-275. http://www.ncbi.nlm.nih.gov/pubmed/14907713

18. Tobe, T., T. Hayashi, C.G. Han, G.K. Schoolnik, E. Ohtsubo and C. Sasakawa, 1999. Complete DNA sequence and structural analysis of the enteropathogenic Escherichia coli adherence factor plasmid. Infect. Immunol., 67: 5455-5462. http://www.ncbi.nlm.nih.gov/pubmed/10496929

19. Ramirez, K., R. Huerta, E. Oswald, C. Garcia-Tovar, J.M. Hernandez and F. Navarro-Garcia, 2005. Role of EspA and intimin in expression of proinflammatory cytokines from enterocytes and lymphocytes by rabbit enteropathogenic Escherichia coli-infected rabbits. Infect. Immunol., 73: 103-113. http://iai.asm.org/cgi/content/abstract/73/1/103

20. Bernardini, M.L., M.G. Sanna, A. Fontaine and P.J. Sansonetti, 1993. OmpC is involved in invasion of epithelial cells by Shigella flexneri. Infect. Immunol., 61: 3625-3635.

http://www.pubmedcentral.nih.gov/articlerender.fc gi?artid=281057

21. Jerse, A.E., K.G. Gicquelais and J.B. Kaper, 1991. Plasmid and chromosomal elements involved in the pathogenesis of attaching and effacing Escherichia coli. Infect. Immunol., 59: 3869-3875. http://www.pubmedcentral.nih.gov/articlerender.fc gi? $\operatorname{artid}=258970$

22. Scaletsky, I.C., M.S. Gatti, J.F. da Silveira, I.M. DeLuca, E. Freymuller and L.R. Travassos, 1995. Plasmid coding for drug resistance and invasion of epithelial cells in enteropathogenic Escherichia coli 0111:H. Microb. $\quad$ Pathog., 18: 387-399. http://www.ncbi.nlm.nih.gov/pubmed/8551942 
23. Raja, S.B., M.R. Murali and S.N. Devaraj, 2008. Differential expression of $O m p C$ and $O m p F$ in multidrug-resistant Shigella dysenteriae and Shigella flexneri by aqueous extract of Aegle marmelos, altering its susceptibility toward betalactam antibiotics. Diagn. Microbiol. Infect. Dis., 61: 321-328.

http://www.ncbi.nlm.nih.gov/pubmed/18358664

24. Yoshida, T., L. Qin, A.E. Linda and I. Masayori, 2006. Transcription regulation of $O m p F$ and $O m p C$ by a single transcription factor, OmpR. J. Biol. Chem., 281: 17114-17123. http://www.ncbi.nlm.nih.gov/pubmed/16618701
25. Aiba, H., T. Mizuno and S. Mizushima, 1989. Transfer of phosphoryl group between two regulatory proteins involved in osmoregulatory expression of the OmpF and OmpC genes in Escherichia coli. J. Biol. Chem., 264: 8563-8567. http://cat.inist.fr/?aModele $=$ afficheN\&cpsidt $=7312$ 784

26. Russo, F.D. and T.J. Silhavy, 1991. EnvZ controls the concentration of phosphorylated $O m p R$ to mediate osmoregulation of the porin genes. J. Mol. Biol., 222

567-580. http://www.ncbi.nlm.nih.gov/pubmed/1660927 